\title{
Peixes como indicadores da qualidade ambiental do ribeirão Esperança, município de Londrina, Paraná, Brasil
}

\author{
Daniel Bartolomei Vieira ${ }^{1,3}$ \& Oscar Akio Shibatta ${ }^{2}$ \\ Biota Neotropica v7 (n1) - http://www.biotaneotropica.org.br/v7n1/pt/abstract?article +bn01407012007 \\ Recebido em 27/09/06 \\ Versão reformulada recebida em 20/12/06 \\ Publicado em 15/02/2007 \\ ${ }^{1}$ Programa de Pós-Graduação em Ciências Biológicas, Zoologia, Centro de Ciências Biológicas, \\ Departamento de Biologia Animal e Vegetal, Universidade Estadual de Londrina \\ ${ }^{2}$ Centro de Ciências Biológicas, Departamento de Biologia Animal e Vegetal, \\ Universidade Estadual de Londrina, Campus Universitário, CP 6001, \\ CEP 86051-990, Londrina, Paraná, Brasil,e-mail: shibatta@uel.br \\ ${ }^{3}$ Autor para correspondência: Daniel Bartolomei Vieira, e-mail: dabavi@ gmail.com
}

\begin{abstract}
Vieira, D.B. \& Shibatta, O.A. Fishes as indicators of ribeirão Esperança environmental quality, Londrina municipality, Paraná, Brazil. Biota Neotrop. Jan/Apr 2007 vol. 7, no. 1 http://www.biotaneotropica.org.br/v7n1/pt/abstract?article+bn01407012007 ISSN 1676-0603.

To evaluate the environmental quality and patterns of diversity of fish species from an altered urban stream, we analyzed habitat quality, water velocity and fish species distribution. In order to include a larger amount of environments and considering the distinct physical characteristics and human influence, five stream sites were seasonally sampled. A total of 5,426 individuals, being 12 species and 6 orders, were collected. The degree of environmental alteration at each sampling site was determined through the analysis of habitat diversity and water velocity. The intermediate sites showed higher species richness as the upper sites were the most altered ones. The lower sites showed adverse physical characteristics to the permanence of some species. These results indicated that hydrological and geomorphological characteristics should influence the aquatic biota richness. Nonetheless, it was found that native species still find favorable places to their development, even with exotic species that have became abundant and are potential competitors in environmental and resources exploration.
\end{abstract}

Keywords: fish diversity, habitat diversity, streams, urban area, water quality.

\section{Resumo}

Vieira, D.B. \& Shibatta, O. A. Peixes como indicadores da qualidade ambiental do ribeirão Esperança, município de Londrina, Paraná, Brasil. Biota Neotrop. Jan/Apr 2007 vol. 7, no. 1 http://www.biotaneotropica.org.br/v7n1/pt/abstract?article+bn01407012007 ISSN 1676-0603.

Com o objetivo de se avaliar a qualidade do ambiente e os padrões de diversidade das espécies de peixes de um riacho urbano alterado, foram feitas avaliações da qualidade de hábitats, análises da velocidade da água e levantamento da distribuição das espécies de peixes. Para abranger uma quantidade maior de ambientes, cinco trechos ao longo do ribeirão foram escolhidos para quatro coletas sazonais da ictiofauna, em função de suas diferentes características físicas e influência da ação humana. Um total de 5.426 espécimes, de 12 espécies e 6 ordens, foi coletado. Através da análise da diversidade de hábitats e da velocidade da água, foi possível determinar qual a situação de alteração ambiental de cada trecho de coleta. Os trechos intermediários apresentaram uma maior riqueza de espécies, pois os trechos de cabeceira são mais alterados, enquanto os trechos de foz apresentam velocidade da água adversa à permanência de algumas espécies. Observou-se também que, apesar de poluído, a riqueza da biota aquática de um curso d'água também pode ser influenciada pelas suas características hidrológicas e geomorfológicas. Além disso, as espécies nativas ainda encontram locais propícios ao seu desenvolvimento, mesmo com a presença de espécies exóticas que se tornaram abundantes e são potenciais competidores na exploração do ambiente e seus recursos.

Palavras-chave: diversidade de hábitats, diversidade de peixes, qualidade da água, região urbana, riachos. 


\section{Introdução}

Avaliar a qualidade ambiental não é uma tarefa simples. Wooton (1990) ressalta que isso vem sendo feito através da análise de parâmetros físicos e químicos da água, como o oxigênio dissolvido, a condutividade, o $\mathrm{pH}$, a temperatura, a salinidade, o oxigênio dissolvido e a turbidez. Entretanto, em se tratando da qualidade da água, observamos que esses parâmetros geralmente são empregados com um enfoque voltado ao consumo humano, estabelecendo valores que demonstram os níveis de potabilidade, mas não se preocupando, necessariamente, com a manutenção da biota aquática. Além disso, somente o uso destes parâmetros não é suficiente para retratar a realidade de um ambiente, necessitando de indicadores biológicos para serem mais eficientes (Wooton 1990, Castro \& Casatti 1997, Smith et al. 1997), e os peixes são excelentes para esse propósito (Karr 1981, Smith et al. 1997, Araújo 1998).

Abordagens mais modernas, como a análise do índice de integridade biótica (Karr 1981), são então desejáveis por tratar dos organismos diretamente envolvidos com o ambiente. Entretanto, para se obter esses índices, esbarra-se em dois problemas muito sérios. $\mathrm{O}$ primeiro se refere ao baixo conhecimento da ecologia e biologia dos organismos aquáticos, o que impede de estabelecer critérios que realmente demonstram a integridade biótica e, tampouco, valorá-los com segurança. Outro problema está relacionado aos ambientes de referência, raramente presentes nas regiões mais populosas, e que são extremamente necessários para o estabelecimento dos limites de cada categoria de qualidade ambiental. Em muitas regiões da bacia do alto Paraná é difícil, senão impossível, encontrar locais onde as comunidades de peixes não foram alteradas. Os riachos urbanos do município de Londrina não são uma exceção e alterações em cursos d'água dessa região já foram registradas em outros trabalhos (Shibatta et al. 2002, Oliveira \& Benemann 2005).

$\mathrm{Na}$ tentativa de se utilizar peixes como indicadores da qualidade ambiental, empregamos um princípio simples, que seria o do aumento da riqueza de espécies com o aumento dessa qualidade. Para isso, também foi realizada uma análise da complexidade estrutural do ambiente e da diversidade de hábitats, pois existe uma forte relação entre a disponibilidade de habitas e sua biodiversidade (Galdean et al. 2000). A utilização de protocolos para avaliação da qualidade de hábitats é útil para estimar quão alterados esses ambientes estão, principalmente quando analisados junto com a biota (Karr 1981, Smith et al. 1997, Callisto et al. 2001). Entretanto, essa hipótese, aparentemente fácil de ser testada, não gera uma relação tão imediata, como apresentaremos a seguir. Desta forma, este estudo foi feito com a intenção de se avaliar a qualidade do ambiente e os padrões de riqueza de espécies de peixes que vivem em um curso d'água urbano notadamente alterado.

\section{Material e Métodos}

O ribeirão Esperança, situado no Terceiro Planalto Paranaense (ou Planalto de Guarapuava), é um afluente de terceira ordem do baixo rio Tibagi, em sua margem esquerda. Tem sua nascente entre os municípios de Londrina e Cambé e deságua no ribeirão Cafezal, no município de Londrina. Ao longo de seu curso, de cerca de $23 \mathrm{~km}$, recebe as águas de um afluente principal, o córrego Cebolão e de vários outros pequenos cursos não identificados por nomes, vários deles provenientes de galerias de águas pluviais, mas também de pequenas nascentes naturais. $O$ ribeirão atravessa a zona urbana na divisa dos dois municípios e depois adentra o município de Londrina, por onde passa por trechos com características agrícolas e retorna para trechos com características urbanas antes de sua foz.

Ao longo de sua extensão, o ribeirão Esperança sofre influências do homem, principalmente pela implantação de condomínios residenciais em áreas próximas. A ausência de mata ciliar é evidente em boa parte dos trechos. De modo a abranger uma quantidade maior de ambientes, valorizando a heterogeneidade ambiental, cinco trechos ao longo do ribeirão foram escolhidos para a coleta da ictiofauna. Um trecho mais à montante (Trecho 1 - Figura 1a), um trecho alto médio (Trecho 2 - Figura $1 \mathrm{~b}$ ), um trecho médio (Trecho 3 - Figura 1c), um trecho médio baixo (Trecho 4 - Figura 1d) e, por último, um trecho próximo à jusante (Trecho 5 - Figura 1e).

O Trecho 1 apresenta águas mais rápidas e rasas, com $40 \mathrm{~cm}$ de profundidade média, poucos remansos, ficando estes principalmente nas curvas ou após obstáculos durante o curso. O leito é encaixado, com as margens bastante altas e sujeitas à erosão. O substrato é variado, mas de modo geral com pouca lama e muito entulho de obras civis e pequenas pedras. Enquanto a vegetação marginal de gramíneas é abundante, a mata ciliar é escassa e é possível registrar a presença de intensa ação do homem devido ao acúmulo de uma variedade de tipos de lixo doméstico nas margens e no leito. O trecho é predominantemente cercado por áreas de características agrícolas.

O Trecho 2 é o mais raso, com $27 \mathrm{~cm}$ de profundidade média. É correntoso e com poucos remansos, encontrados somente após as curvas. Houve nas proximidades do local a construção de um condomínio residencial e de uma galeria para escoamento de água que desemboca diretamente e sem controle dentro do ribeirão Esperança à montante do trecho. A água é muito turva e o substrato bastante argiloso, pois o local sofre com excessivo assoreamento, e seu agravamento foi registrado visualmente ao longo das coletas. Em compensação, a mata ciliar no trecho é pouco mais preservada e vistosa, assim como a vegetação marginal de gramíneas é abundante. Seus arredores apresentam características urbanas.

O Trecho 3 é o ponto com maior profundidade, com média e $53 \mathrm{~cm}$. Apresenta vários meandros, e, por conseqüência, mais remansos. Apesar da maior profundidade, devido à construção de um condomínio à montante do Trecho 2, seu leito é bastante argiloso e, em alguns pontos mais rasos perto das margens, é possível notar a formação de bancos de terra devido ao assoreamento. A mata ciliar é bem preservada, o que impede que o assoreamento seja ainda maior, uma vez que as margens ficam bastante protegidas, mas não há vegetação marginal de gramíneas. O trecho apresenta características agrícolas.

O Trecho 4 é mais raso que o anterior, com $43 \mathrm{~cm}$ de profundidade média, menor quantidade de remansos e água mais veloz. O trecho ainda sofre com o aporte de terra das partes mais altas e devido à falta de mata ciliar no local. No trecho, o ribeirão faz divisa entre uma propriedade rural e um condomínio residencial, portanto a mata encontra-se comprometida em ambas as margens, devido à agricultura e ao muro do condomínio, respectivamente. A vegetação marginal de gramíneas, entretanto, é abundante.

O Trecho 5 é o mais conservado dos trechos, e apresenta características bem diferenciadas dos outros pontos de coleta. Sua profundidade média é de $39 \mathrm{~cm}$, e o substrato é estritamente rochoso, portanto apresentando pequenas corredeiras com águas bastante velozes, sem a presença de remansos. A mata ciliar é bastante preservada, apesar dos arredores apresentarem característica urbana, mas não há gramíneas nas margens.

A própria distribuição urbana do município de Londrina favoreceu uma preservação maior do Trecho 5 , que apesar de estar dentro de área urbana, seus arredores parecem não ter despertado interesse imobiliário, já que é composta por propriedades tipo "chácara de recreio". Todos os outros trechos, entretanto, exceto o Trecho 3 que fica dentro da Universidade Estadual de Londrina, sofrem com a urbanização, principalmente os trechos de cabeceira onde novos conjuntos residenciais e condomínios estão sendo construídos. 


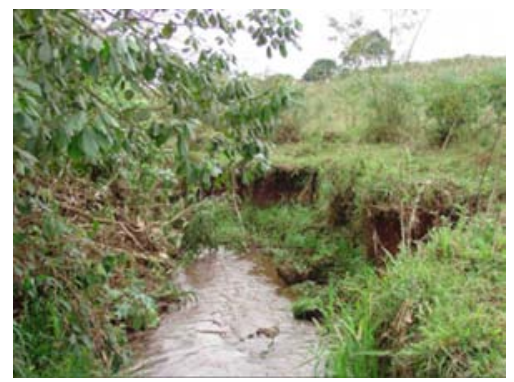

(a)

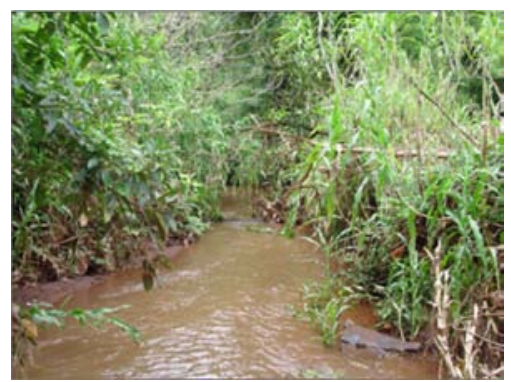

(b)

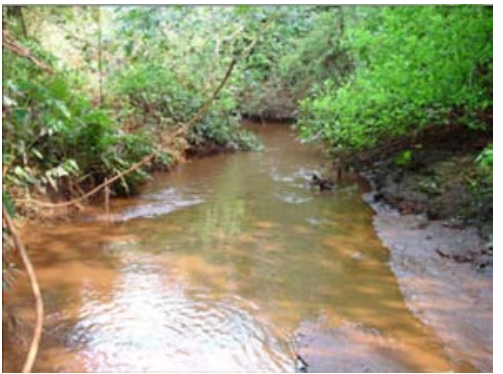

(c)

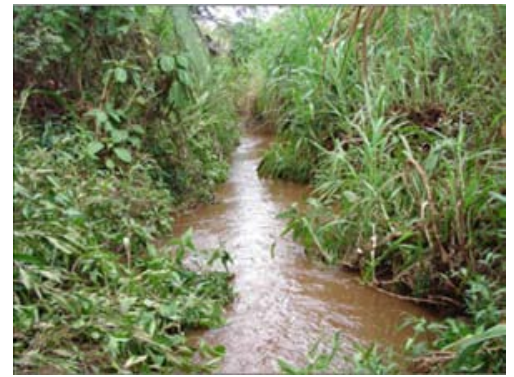

(d)

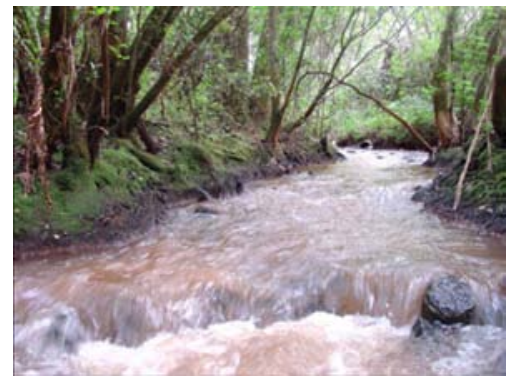

(e)

Figura 1. Trechos de coleta no ribeirão Esperança. A. Trecho 1 (foto: P. Veduatto); B. Trecho 2; C. Trecho 3; D. Trecho 4; e E. Trecho 5 (fotos: D. B. Vieira).
As coletas foram realizadas em quatro períodos do ano de 2005, em março, junho, setembro e novembro, para desta forma abranger as estações do ano. Em cada ponto de coleta, um trecho de $50 \mathrm{~m}$ foi cercado com redes de malha fina $(2 \mathrm{~mm})$ e os peixes presentes nesta extensão foram coletados utilizando-se tarrafas com malha de $2 \mathrm{~cm}$ entre nós opostos, peneiras e arrastos de telas do tipo sombrite. A única exceção foi o Trecho 5, que não foi cercado pois a velocidade da correnteza não permitia a instalação dessas redes de contenção. Entretanto, uma área de igual extensão foi demarcada e os peixes foram ali coletados com os mesmos aparelhos de coletas.

Os espécimes coletados foram medidos com paquímetro digital com precisão de $0,01 \mathrm{~mm}$, pesados em balança digital com precisão de $0,001 \mathrm{~g}$ para cálculo de biomassa, fixados em formol e depositados no Museu de Zoologia da Universidade Estadual de Londrina (MZUEL), depois de devidamente identificados usando-se chaves apresentadas em Castro et al. $(2003 ; 2004)$.

Para a qualificação do ambiente, foi utilizado um protocolo de avaliação rápida da diversidade de hábitats, segundo Callisto et al. (2001) (Anexo A). Esse protocolo consiste de uma pontuação (numa escala de 0 a 3) para cada parâmetro de hábitat, dividido em 11 categorias. Conforme maior a pontuação, melhor a qualidade do ambiente aquático analisado.

Também, em cada trecho de coleta foram obtidas a velocidade da água, através do "método do flutuador", que consiste em demarcar um trecho de $5 \mathrm{~m}$ e esperar que um flutuador percorra a distância demarcada, anotando-se o tempo de cinco repetições, para que seja feita uma média de tempo, e então é aplicada a fórmula para o cálculo da velocidade $(\mathrm{V}=\Delta \mathrm{s} / \Delta \mathrm{t})$.

Com os resultados das capturas dos peixes para cada trecho de coleta foram determinados o número de espécies (riqueza) (Odum 1988), a diversidade, a equitabilidade e a dominância (Magurran 1988). A diversidade foi calculada através do índice de Shannon-Wiener, que assume que os indivíduos são uma amostra aleatória de uma população "indefinidamente grande" e que todos os indivíduos estão representados na amostra (Magurran 1988). A dominância foi determinada pelo índice de Simpson, que é usado para se determinar a abundância das espécies mais comuns ao invés de fornecer, simplesmente, uma medida de riqueza de espécies. Os valores de dominância são dados pela subtração do índice de Simpson de 1 (um) $(\mathrm{D}=1-\mathrm{S})$. Estes índices foram analisados com auxílio do pacote estatístico PAST (Hammer et al. 1999).

\section{Resultados}

Através da qualificação do ambiente (Tabelas 1 e 2) foi possível determinar a situação ambiental de cada trecho de coleta. Segundo as variáveis analisadas, o Trecho 5 foi o que apresentou maior pontuação, ou seja, o de melhor qualidade ambiental. Além disso, esse trecho manteve uma constância nessa pontuação ao longo do tempo, com todas as coletas apresentando 21 pontos. O Trecho 1 foi o seguinte na ordem de qualidade, embora sua pontuação tenha sido bem inferior ao Trecho 5 e não sendo tão constante (mediana de 11 pontos). A seguir vêm os Trechos 4 e 3 com uma mediana de 9 e 8 pontos, respectivamente. Já no Trecho 2 foi onde houve a menor pontuação em termos de qualidade de ambientes, com mediana de 5,5 pontos (Tabela 2 ).

A velocidade da água do ribeirão Esperança variou de 0,2 a $0,9 \mathrm{~m} . \mathrm{s}^{-1}$, apresentando maior velocidade média no trecho 5 (Tabela 3). Foi possível notar, ainda, que há uma mescla de características, com as águas mais rápidas ocorrendo em locais mais rasos e as águas mais lentas em locais mais profundos.

Ao todo, foram coletados 5.426 indivíduos, distribuídos em 13 espécies nas ordens Characiformes, Siluriformes, 
Tabela 1. Qualificação do ambiente dos cinco trechos de coleta no ribeirão Esperança, segundo modelo de avaliação de hábitats de Callisto et al. (2001) (Anexo A). $\mathrm{m}=$ março/2005; $\mathrm{j}=$ junho/2005; $\mathrm{s}=$ setembro/2005; $\mathrm{n}=$ novembro/2005; $\mathrm{O}=$ ótimo; $\mathrm{SO}=$ sub-ótimo; $\mathrm{M}=$ mediano; $\mathrm{P}=$ pobre.

Table 1. Environment qualification in five collection streches in ribeirão Esperança, according to model of habitats evaluation of Callisto et al. (2001) (Annex A). $\mathrm{m}=$ may/2005; $\mathrm{j}=$ june/2005; $\mathrm{s}=$ september/2005; $\mathrm{n}=$ november $/ 2005 ; \mathrm{O}=$ great; $\mathrm{SO}=$ sub-great; $\mathrm{M}=$ medium; $\mathrm{P}=$ poor.

\begin{tabular}{|c|c|c|c|c|c|c|c|c|c|c|c|c|c|c|c|c|c|c|c|c|}
\hline \multirow{2}{*}{$\begin{array}{c}\text { Variáveis de } \\
\text { hábitat }\end{array}$} & \multicolumn{4}{|c|}{ Trecho 1} & \multicolumn{4}{|c|}{ Trecho 2} & \multicolumn{4}{|c|}{ Trecho 3} & \multicolumn{4}{|c|}{ Trecho 4} & \multicolumn{4}{|c|}{ Trecho 5} \\
\hline & $\mathbf{m}$ & $\mathbf{J}$ & ws & $\mathbf{n}$ & M & $\mathbf{J}$ & $\mathbf{S}$ & $\mathrm{n}$ & $\mathbf{m}$ & $\mathbf{j}$ & $\mathbf{S}$ & $\mathrm{n}$ & $\mathbf{m}$ & $\mathbf{j}$ & $\mathrm{s}$ & $\mathbf{n}$ & $\mathbf{m}$ & $\mathbf{J}$ & $\mathbf{s}$ & $\mathbf{N}$ \\
\hline 1 & M & M & M & M & $\mathrm{P}$ & $\mathrm{P}$ & $\mathrm{P}$ & $P$ & $\mathrm{P}$ & $\mathrm{P}$ & $\mathrm{P}$ & $\mathrm{P}$ & - & $\mathrm{P}$ & $\mathrm{P}$ & $\mathrm{P}$ & SO & SO & SO & SO \\
\hline 2 & M & M & M & M & $\mathrm{P}$ & $\mathrm{P}$ & $\mathrm{P}$ & $\mathrm{P}$ & M & M & M & M & - & M & M & M & $\mathrm{P}$ & $\mathrm{P}$ & $\mathrm{P}$ & $\mathrm{P}$ \\
\hline 3 & $\mathrm{M}$ & $\mathrm{M}$ & $\mathrm{M}$ & $\mathrm{M}$ & $\mathrm{P}$ & $\mathrm{P}$ & $\mathrm{P}$ & $\mathrm{P}$ & $\mathrm{M}$ & $\mathrm{M}$ & $\mathrm{M}$ & $\mathrm{M}$ & - & $\mathrm{M}$ & $\mathrm{M}$ & $\mathrm{M}$ & $\mathrm{P}$ & $\mathrm{P}$ & $\mathrm{P}$ & $\mathrm{P}$ \\
\hline 4 & M & M & M & M & $\mathrm{P}$ & $\mathrm{P}$ & $\mathrm{P}$ & $\mathrm{P}$ & $\mathrm{P}$ & $\mathrm{P}$ & $\mathrm{P}$ & $\mathrm{P}$ & - & $\mathrm{P}$ & $\mathrm{P}$ & $\mathrm{P}$ & M & M & M & M \\
\hline 5 & SO & M & M & M & $\mathrm{P}$ & $\mathrm{P}$ & $\mathrm{P}$ & $\mathrm{P}$ & $\mathrm{P}$ & $\mathrm{P}$ & $\mathrm{P}$ & $\mathrm{P}$ & - & $\mathrm{P}$ & $\mathrm{P}$ & $\mathrm{P}$ & $\mathrm{O}$ & $\mathrm{O}$ & $\mathrm{O}$ & $\mathrm{O}$ \\
\hline 6 & M & M & M & M & $\mathrm{P}$ & $\mathrm{P}$ & $\mathrm{P}$ & $\mathrm{P}$ & $\mathrm{P}$ & $\mathrm{P}$ & $\mathrm{P}$ & $\mathrm{P}$ & - & $\mathrm{P}$ & $\mathrm{P}$ & $\mathrm{P}$ & $\mathrm{O}$ & $\mathrm{O}$ & $\mathrm{O}$ & $\mathrm{O}$ \\
\hline 7 & $\mathrm{O}$ & $\mathrm{O}$ & $\mathrm{O}$ & $\mathrm{O}$ & SO & SO & SO & $\mathrm{SO}$ & SO & $\mathrm{O}$ & SO & $\mathrm{SO}$ & - & SO & SO & M & $\mathrm{O}$ & $\mathrm{O}$ & $\mathrm{O}$ & $\mathrm{O}$ \\
\hline 8 & M & M & M & M & M & M & M & M & M & M & M & M & - & $\mathrm{O}$ & $\mathrm{O}$ & SO & $\mathrm{O}$ & $\mathrm{O}$ & $\mathrm{O}$ & $\mathrm{O}$ \\
\hline 9 & $\mathrm{P}$ & $\mathrm{P}$ & $\mathrm{P}$ & $\mathrm{P}$ & M & M & M & M & M & M & M & M & - & $\mathrm{P}$ & $\mathrm{P}$ & $\mathrm{P}$ & SO & SO & SO & SO \\
\hline 10 & M & M & $\mathrm{P}$ & M & M & M & $\mathrm{P}$ & $\mathrm{P}$ & M & M & $\mathrm{P}$ & M & - & M & M & M & $\mathrm{SO}$ & SO & SO & SO \\
\hline 11 & $\mathrm{P}$ & $\mathrm{P}$ & $\mathrm{P}$ & $\mathrm{P}$ & M & M & M & M & M & M & M & M & - & M & M & $\mathrm{P}$ & $\mathrm{SO}$ & SO & SO & SO \\
\hline
\end{tabular}

Tabela 2. Pontuação dos parâmetros ambientais em cada trecho de coleta do ribeirão Esperança, levando em conta a sua qualidade, segundo modelo de avaliação de hábitats de Callisto et al. (2001). O = ótimo; $\mathrm{SO}=$ sub-ótimo; $\mathrm{M}=$ mediano; $\mathrm{P}=$ pobre.

Table 2. Environmental parameters punctuation in each stretch of ribeirão Esperança, regarding its quality, according model of habitats evaluation of Callisto et al. (2001). $\mathrm{O}=$ great; $\mathrm{SO}=$ sub-great; $\mathrm{M}=$ medium; $\mathrm{P}=$ poor.

\begin{tabular}{|c|c|c|c|c|c|c|c|}
\hline \multicolumn{8}{|c|}{ Pontuação } \\
\hline & & \multirow[t]{2}{*}{ O (3 ptos) } & \multirow[t]{2}{*}{ SO (2 ptos) } & \multirow[t]{2}{*}{ M (1 pto) } & \multirow[t]{2}{*}{$\mathbf{P}(0$ ptos $)$} & \multicolumn{2}{|c|}{ Total } \\
\hline & & & & & & Mín-Máx & Mediana \\
\hline \multirow[t]{4}{*}{ Trecho 1} & $03 / 2005$ & $1 \times 3=3$ & $1 \times 2=2$ & $7 \times 1=7$ & $2 \times 0=0$ & 10-12 & 11 \\
\hline & $06 / 2005$ & $1 \times 3=3$ & $0 \times 2=0$ & $8 \times 1=8$ & $2 \times 0=0$ & & \\
\hline & $09 / 2005$ & $1 \times 3=3$ & $0 \times 2=0$ & $7 \times 1=7$ & $3 \times 0=0$ & & \\
\hline & $11 / 2005$ & $1 \times 3=3$ & $0 \times 2=0$ & $8 \times 1=8$ & $2 \times 0=0$ & & \\
\hline \multirow[t]{4}{*}{ Trecho 2} & $03 / 2005$ & $0 \times 3=0$ & $1 \times 2=2$ & $4 \times 1=4$ & $6 \times 0=0$ & $5-6$ & 5,5 \\
\hline & $06 / 2005$ & $0 \times 3=0$ & $1 \times 2=2$ & $4 \times 1=4$ & $6 \times 0=0$ & & \\
\hline & $09 / 2005$ & $0 \times 3=0$ & $1 \times 2=2$ & $3 \times 1=3$ & $7 \times 0=0$ & & \\
\hline & $11 / 2005$ & $0 \times 3=0$ & $1 \times 2=2$ & $3 \times 1=3$ & $7 \times 0=0$ & & \\
\hline \multirow[t]{4}{*}{ Trecho 3} & $03 / 2005$ & $0 \times 3=0$ & $1 \times 2=2$ & $6 \times 1=6$ & $4 \times 0=0$ & $7-8$ & 8 \\
\hline & $06 / 2005$ & $0 \times 3=0$ & $1 \times 2=2$ & $6 \times 1=6$ & $4 \times 0=0$ & & \\
\hline & $09 / 2005$ & $0 \times 3=0$ & $1 \times 2=2$ & $5 \times 1=5$ & $5 \times 0=0$ & & \\
\hline & $11 / 2005$ & $0 \times 3=0$ & $1 \times 2=2$ & $6 \times 1=6$ & $4 \times 0=0$ & & \\
\hline \multirow[t]{4}{*}{ Trecho 4} & $03 / 2005$ & - & - & - & - & $6-9$ & 9 \\
\hline & $06 / 2005$ & $1 \times 3=3$ & $1 \times 2=2$ & $4 \times 1=4$ & $5 \times 0=0$ & & \\
\hline & $09 / 2005$ & $1 \times 3=3$ & $1 \times 2=2$ & $4 \times 1=4$ & $5 \times 0=0$ & & \\
\hline & $11 / 2005$ & $0 \times 3=0$ & $1 \times 2=2$ & $4 \times 1=4$ & $7 \times 0=0$ & & \\
\hline \multirow[t]{4}{*}{ Trecho 5} & $03 / 2005$ & $4 \times 3=12$ & $4 \times 2=8$ & $1 \times 1=1$ & $2 \times 0=0$ & 21 & 21 \\
\hline & $06 / 2005$ & $4 \times 3=12$ & $4 \times 2=8$ & $1 \times 1=1$ & $2 \times 0=0$ & & \\
\hline & $09 / 2005$ & $4 \times 3=12$ & $4 \times 2=8$ & $1 \times 1=1$ & $2 \times 0=0$ & & \\
\hline & $11 / 2005$ & $4 \times 3=12$ & $4 \times 2=8$ & $1 \times 1=1$ & $2 \times 0=0$ & & \\
\hline
\end{tabular}

Gymnotiformes, Synbranchiformes, Perciformes e Cyprinodontiformes (Tabela 4). As espécies mais abundantes foram Poecilia reticulata com 4.325 indivíduos (79\% do total de espécies), seguido por Hypostomus ancistroides $(\mathrm{n}=897 ; 17 \%)$, Xiphophorus helleri $(\mathrm{n}=89 ; 2 \%)$ e Geophagus brasiliensis $(\mathrm{n}=69 ; 1 \%)$. As outras espécies somaram apenas o $1 \%$ restante.

Os valores dos índices de diversidade de Shannon-Wiener (H') e o índice de dominância de Simpson (Tabela 4) foram diferentes entre os trechos. O Trecho 3, com maior riqueza de espécies (10), também é o local com maior diversidade e menor dominância. $\mathrm{O}$ Trecho 1, entretanto, teve a menor diversidade e a maior dominância, devido ao predomínio da espécie exótica Poecilia reticulata. Já no Trecho 5, considerado o local com melhor qualidade ambiental conforme a análise do protocolo de avaliação de hábitats, apresentou os segundos menores valores de diversidade e dominância de espécies. Os Trechos 2 e 4, ambos com sete espécies coletadas, apresentaram 
Tabela 3. Valores mínimos, máximos, médias e desvio padrão da velocidade da água (m/s) em cinco trechos do ribeirão Esperança.

Table 3. Minimum, maximum, averages and standard deviation values of drift speed (m/s) in five stretches of ribeirão Esperança.

\begin{tabular}{ccc}
\hline & Mínimo-máximo & Média \pm desvio padrão \\
\hline Trecho 1 & $0,4-0,5$ & $0,5 \pm 0,1$ \\
Trecho 2 & $0,2-0,6$ & $0,4 \pm 0,2$ \\
Trecho 3 & $0,3-0,4$ & $0,4 \pm 0,1$ \\
Trecho 4 & $0,3-0,4$ & $0,4 \pm 0,1$ \\
Trecho 5 & $0,6-0,9$ & $0,7 \pm 0,1$ \\
\hline
\end{tabular}

Tabela 4. Total de exemplares coletados por espécie em cada trecho e em cada coleta no ribeirão Esperança. $m=$ março/2005; $j=j u n h o / 2005 ; \mathrm{s}=\mathrm{setembro} / 2005$; n = novembro/2005; $\mathrm{n}$ = abundância; H' = índice de diversidade de Shannon-Wiener; E = equitabilidade; D = dominância.

Table 4. Total of specimens collected by species in each stretch and in each sample in the ribeirão Esperança. $m=$ may $/ 2005 ; j=j u n e / 2005 ; s=$ september $/ 2005$; $\mathrm{n}=$ november/2005; $\mathrm{n}=$ abundance; $\mathrm{H}^{\prime}=$ Shannon-Wiener diversity index; $\mathrm{E}=$ equitability; $\mathrm{D}=$ dominance.

\begin{tabular}{|c|c|c|c|c|c|c|}
\hline \multirow[t]{2}{*}{ Espécies } & \multicolumn{5}{|c|}{ Trecho de coleta } & \multirow[b]{2}{*}{$\mathbf{N}$} \\
\hline & 1 & 2 & 3 & 4 & 5 & \\
\hline \multicolumn{7}{|l|}{ Characiformes } \\
\hline Astyanax altiparanae & 0 & 0 & 4 & 0 & 0 & 4 \\
\hline Bryconamericus iheringii & 0 & 7 & 5 & 3 & 1 & 16 \\
\hline Characidium zebra & 0 & 0 & 0 & 1 & 0 & 1 \\
\hline Hoplias malabaricus & 0 & 0 & 1 & 0 & 0 & 1 \\
\hline \multicolumn{7}{|l|}{ Siluriformes } \\
\hline Callichthys callichthys & 0 & 1 & 0 & 0 & 0 & 1 \\
\hline Hypostomus ancistroides & 448 & 192 & 147 & 80 & 30 & 897 \\
\hline Rhamdia quelen & 5 & 9 & 5 & 2 & 1 & 22 \\
\hline \multicolumn{7}{|l|}{ Gymnotiformes } \\
\hline Gymnotus carapo & 1 & 0 & 0 & 0 & 0 & 2 \\
\hline \multicolumn{7}{|l|}{ Synbranchiformes } \\
\hline Synbranchus marmoratus & 0 & 0 & 1 & 0 & 0 & 1 \\
\hline \multicolumn{7}{|l|}{ Perciformes } \\
\hline Geophagus brasiliensis & 0 & 0 & 64 & 5 & 0 & 69 \\
\hline \multicolumn{7}{|l|}{ Cyprinodontiformes } \\
\hline Poecilia reticulata & 3380 & 437 & 350 & 146 & 11 & 4324 \\
\hline Xiphophorus hellerii & 5 & 41 & 43 & 0 & 0 & 89 \\
\hline Total de indivíduos & 3839 & 687 & 620 & 237 & 43 & 5426 \\
\hline Riqueza de espécies & 5 & 6 & 9 & 6 & 4 & \\
\hline Diversidade (H') & 0,38 & 0,93 & 1,22 & 0,87 & 0,77 & \\
\hline Equitabilidade (E) & 0,24 & 0,52 & 0,55 & 0,48 & 0,56 & \\
\hline Dominância (D) & 0,79 & 0,49 & 0,39 & 0,49 & 0,55 & \\
\hline
\end{tabular}

valores intermediários e bastante próximos de diversidade, eqüitabilidade e dominância.

Analisando o gráfico de correlação entre as riquezas de espécies e os índices de qualidade ambiental foi possível notar que à medida que a qualidade aumentou, houve diminuição da riqueza (Figura 2). O mesmo padrão pode ser observado entre a riqueza de espécies e a velocidade da água (Figura 3). Além disso, a correlação entre a velocidade da água e a qualidade do ambiente foi elevada (Figura 4). As correlações entre o índice de diversidade de ShannonWiener, equitabilidade e dominânica, com a qualidade ambiental foram muito baixas $\left(\mathrm{R}^{2}=0,1116 ; 0,0162 ; 0,0665\right.$, respectivamente).

\section{Discussão}

A redução da riqueza de espécies com o aumento da qualidade ambiental é o resultado que mais se destacou, pois aparentemente con- traria os argumentos de Galdean et al. (2000), que diz que existe uma forte relação entre a disponibilidade de habitas e sua biodiversidade. Além disso, constatou-se que a quantidade de indivíduos coletados diminuiu conforme se aproximava da jusante do ribeirão, enquanto a riqueza de espécies foi maior nos trechos intermediários e menor nos trechos a montante e a jusante, que não é a tendência natural do que acontece em um rio neotropical, onde a riqueza de espécies tende a aumentar da cabeceira para a foz (Garutti 1988, Bennemann et al. 1995). Esse desvio de padrão pode estar relacionado com as características físicas dos trechos mais a jusante, onde a maior velocidade da correnteza e a diminuição de hábitats com características de poções provavelmente seja o fator que reduz a riqueza de espécies nesses locais, bem como a quantidade de indivíduos coletados, pois não propicia hábitats para todas as espécies, apenas para as mais 


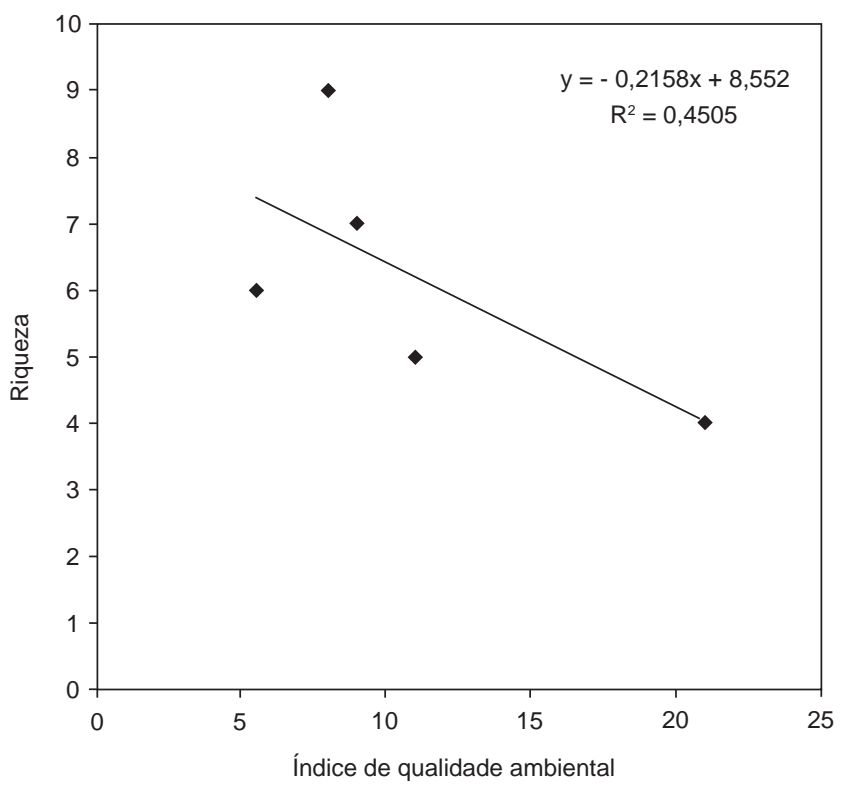

Figura 2. Correlação linear entre riqueza de espécies de peixes e o índice de qualidade ambiental do ribeirão Esperança.

Figure 2. Linear correlation between fish species richness and environmental quality index of ribeirão Esperança.

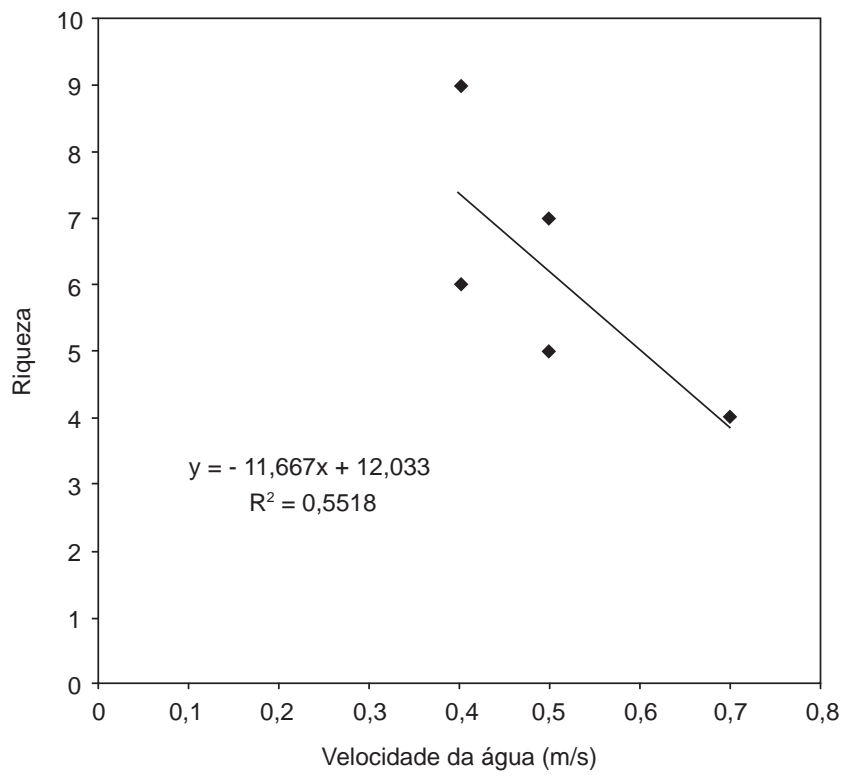

Figura 3. Correlação linear entre a riqueza de espécies de peixes e a velocidade da água do ribeirão Esperança.

Figure 3. Linear correlation between fish species richness and drift speed of ribeirão Esperança.

adaptadas a essa condição, servindo como um trecho de passagem para outras espécies.

Outro fator relevante foi a presença de espécies exóticas bem estabelecidas e de espécies resistentes às alterações ambientais. A baixa correlação entre os índices de diversidade e equitabilidade com o índice de qualidade de hábitats provavelmente se deve à dominância elevada das espécies Poecilia reticulata e Hypostomus ancistroides, independentemente das condições ambientais. O valor de dominância dos Trechos 1 e 4, por exemplo, foi alto por causa da abundância de

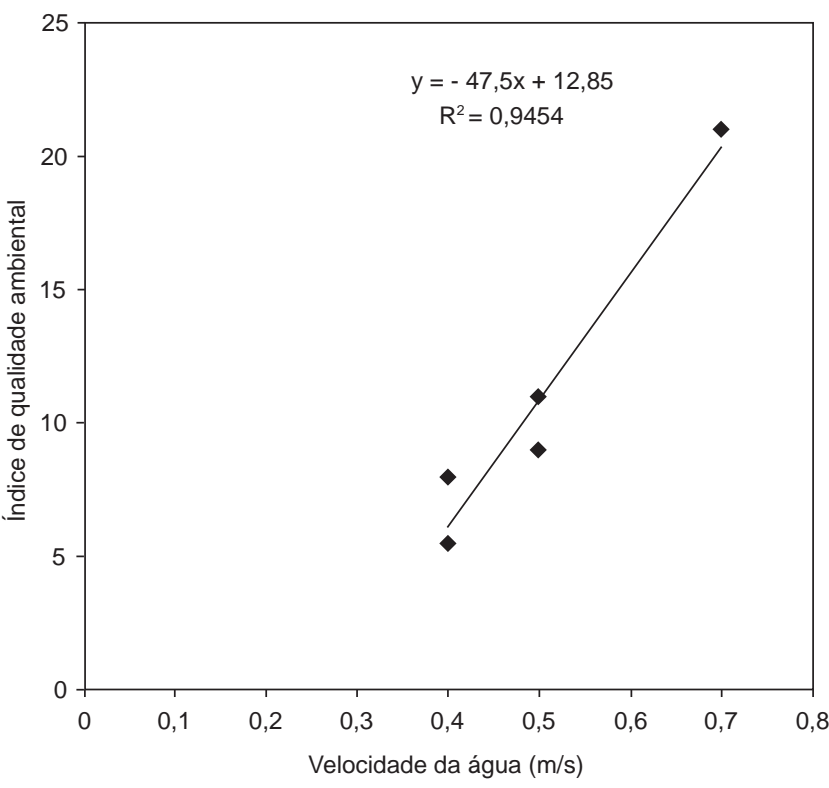

Figura 4. Correlação linear entre o índice de qualidade ambiental e a velocidade da água do ribeirão Esperança.

Figure 4. Linear correlation between environmental quality and drift speed of ribeirão Esperança. $R=97,2 \%$

P. reticulata, e o baixo valor de equitabilidade nesses trechos reforça esse resultado de dominância. Poecilia reticulata, é uma espécie exótica introduzida, de interesse aquarístico, que possui capacidade de resistência em ambientes alterados pelo homem, pois se alimenta de detritos variados, sendo bastante oportunista, como observado por Oliveira \& Bennemann (2005) no ribeirão Cambé, outro riacho urbano do município de Londrina. Essa vantagem da espécie sobre as espécies nativas, bem como sua resistência a altas temperaturas, salinidade e baixas concentrações de oxigênio dissolvido a torna abundante em ambientes alterados (Moyle \& Cech Jr. 1996).

O Trecho 5 apresentou poucas espécies e $H$. ancistroides foi proporcionalmente mais abundante que as outras, inclusive de $P$. reticulata, devido às condições físicas do local, com corredeiras e águas rápidas, o que evidencia a adaptação da espécie a esse hábitat. Mesmo assim, essa espécie também foi abundante nos primeiros trechos de coleta e isto pode estar relacionado com o seu hábito alimentar detritívoro em locais alterados (Oliveira \& Bennemann 2005), embora normalmente se alimente de algas (Britski 1972, Burguess 1989), bem como a capacidade das espécies desse gênero respirar oxigênio do ar devido a trocas gasosas no estômago (Schmidt-Nielsen 1999, Py-Daniel 1984), o que também a coloca em vantagem em ambientes alterados, que são assoreados e que possuem baixas concentrações de oxigênio dissolvido.

Dessa forma, é possível considerar que a baixa diversidade do Trecho 1 está relacionada com a abundância de $P$. reticulata e $H$. ancistroides devido à poluição por efluentes domésticos. No Trecho 5, entretanto, a baixa diversidade e riqueza podem estar relacionados principalmente às próprias características geomorfológicas e hidrológicas do local (rochoso e de correnteza forte), embora o local seja o que apresentou uma melhor qualidade de hábitats, segundo o protocolo de avaliação, com valores ótimos para os itens 5 a 8 . A diversidade, por sua vez, foi maior nas porções intermediárias, principalmente no Trecho 3. Mesmo que seja o trecho com menor velocidade da água, é o que combina uma variedade maior de hábitats, embora sua qualidade esteja bastante comprometida, de acordo com as variáveis apresentadas no protocolo utilizado. Esse cenário mostra 
que, apesar de poluído, um curso d'água também pode influenciar a diversidade da biota aquática através de suas próprias características físicas, estando esta não só relacionada com a qualidade dos hábitats, mas também com a diversidade de hábitats (Rincón 1999, Mérigoux et al. 1998, Callisto et al. 2001) e com os aspectos hidrológicos e geomorfológicos (Wooton 1990, Lowe-McConnell 1999).

Apesar das alterações do ambiente, as espécies nativas ainda têm encontrado hábitats para sua sobrevivência. Por outro lado, a abundância de espécies exóticas como $P$. reticulata pode ser um sinal de que elas estejam competindo pela exploração do ambiente e seus recursos. Estudos de utilização dos micro-hábitats como sugerido por Rincón (1999) e como observado por Mérigoux et al. (1998) em dois riachos na Guiana Francesa, poderiam explicar melhor a utilização dos hábitats por parte das espécies em um ambiente alterado. Como comentado por Castro \& Casatti (1997), levantamentos sobre as espécies de peixes já foram feitos em grande quantidade para a bacia do alto Paraná, e agora é necessário incluir informações gerais sobre os ambientes de riachos não apenas quanto à biota, mas também em relação às características físicas do local e seus parâmetros abióticos.

\section{Agradecimentos}

Agradecemos à Sirlei T. Bennemann, à Lucia Guiliano-Caetano, Heitor Frossard e dois assessores anônimos, pelas valiosas sugestões e correções em diferentes etapas deste trabalho; à CAPES e ao Programa de Mestrado em Ciências Biológicas da Universidade Estadual de Londrina pelo apoio financeiro; aos técnicos do Museu de Zoologia (MZUEL), Edson Santana da Silva e Aparecido de Souza e a todos os estagiários que colaboraram nas coletas do material.

\section{Referências Bibliográficas}

ARAÚJO, F.G. 1998. Adaptação do índice de integridade biótica usando a comunidade de peixes para o rio Paraíba do Sul. Rev. Bras. Biol. 58(4):547-558

BENNEMANN, S.T., SILVA-SOUZA, A. T. \& ROCHA, G. R. A. 1995 Composición ictiofaunistica em cinco localidades de la cuenca del rio Tibagi, PR - Brasil. Interciencia, 20: 7-13.

BRITSKI, H.A. 1972. Peixes de água doce do Estado de São Paulo: sistemática. In Poluição e Psicultura (Comissão Interestadual da Bacia do Paraná-Uruguai org.).Faculdade de Saúde Pública da USP e Instituto de Pesca, São Paulo, p. 79-108.

BURGUESS, W.E. 1989. An atlas of freshwater and marine catfishes: a preliminary survey of the Siluriformes. T.F.H. Publications Inc., EUA.

CALLISTO, M., MORETTI, M. \& GOULART, M. 2001. Macroinvertebrados bentônicos como ferramenta para avaliar a saúde de riachos. Rev. Bras. Rec. Hidr. 6(1):71-82.

CASTRO, R.M.C \& CASATTI, L. 1997. The fish fauna from a small forest stream of the upper Paraná River basin, southeastern Brazil. Ichthyol. Explor. Freshw. 7(4):337-352.

CASTRO, R.M.C., CASATTI, L., SANTOS, H.F., FERREIRA, K.M., RIBEIRO, A.C., BENINE, R.C., DARDIS, G.Z.P., MELO, A.L.A., STOPIGLIA, R., ABREU, T.X., BOCKMANN, F.A., CARVALHO, M., GIBRAN, F.Z. \& LIMA, F.C.T. 2003. Estrutura e composição da ictiofauna de riachos do rio Paranapanema, sudeste e sul do Brasil. Biota Neotropica 3(1): http://www.biotaneotropica.org.br/v3n1/pt/download? article+BN01703012003

CASTRO, R.M.C., CASATTI, L., SANTOS, H.F., MELO, A.L.A., MARTINS, L.S.F., FERREIRA, K.M., GIBRAN, F.Z., BENINE, R.C., CARVALHO, M., RIBEIRO, A.C., ABREU, T.X., BOCKMANN, F.A., PELIÇÃO, G.Z., STOPLIGLIA, R. \& LANGEANI, F. 2004. Estrutura e composição da ictiofauna de riachos da bacia do rio Grande no estado de São Paulo, sudeste do Brasil. Biota Neotropica 4(1): http://www.biotaneotropica. org.br/v4n1/pt/download?article+BN01704012004
GALDEAN, N., CALLISTO, M., BARBOSA, F.A.R. \& ROCHA, L.A. 2000. Lotic ecosystems of Serra do Cipó, southeast Brazil: water quality and a tentative classifications base don the benthic macroinvertebrate community. J. Aquatic Ecos. Health Manag. 3:545-552.

GARUTTI, V. 1988. Distribuição longitudinal da ictiofauna em um córrego da região noroeste do estado de São Paulo, bacia do rio Paraná. Rev. Bras. Biol. 48(4): 747-759.

HAMMER, Ø., HARPER, D.A.T. \& RYAN, P.D. 2001. PAST: paleontological statistics software package for education and data analysis. Palaeontologia Electronica 4(1): http://palaeo-electronica.org/2001_1/ past/issue1_01.htm.

KARR, J.R. 1981. Assessment of biotic integrity using fish communities. Fisheries 6: 21-27.

LOWE-MCCONNELL, R.H. 1999. A fauna de peixes neotropical. In Estudos ecológicos de comunidades de peixes tropicais (R. H. Lowe-McConnell, eds.). EDUSP, São Paulo, p. 129-168.

MAGURRAN A. 1988. Ecological diversity and its measurements. Chapman and Hall, Nova Iorque.

MÉRIGOUX, S., PONTON, D. \& MÉRONA, B. 1998. Fish richness and species-habitat relationships in two coastal streams of French Guiana, South América. Env. Biol. Fish., 51:25-39.

MOYLE, P.B., CECH JR., J.J. 1996. Fishes: an introduction to ichthyology. $3^{\text {rd }}$ ed. Prentice Hall, New Jersey.

ODUM, E. P. 1988. Ecologia. Ed. Guanabara, Rio de Janeiro.

OLIVEIRA, D.C. \& BENNEMANN, S.T. 2005. Ictiofauna, recursos alimentares e relações com as interferências antrópicas em um riacho urbano no sul do Brasil. Biota Neotropica, 5(1): http://www.biotaneotropica.org. br/v5n1/pt/download?article+BN02905012005.

PY-DANIEL, L.H.R. 1984. Sistemática dos Loricariidae (Ostariophysi, Siluroidei) do complexo de lagos do Janauacá, Amazonas e aspectos da sua biologia e ecologia. Dissertação de Mestrado, Instituto Nacional de Pesquisa da Amazônia, Manaus.

RINCÓN, P.A. 1999. Uso do micro-hábitat em peixes de riachos: métodos e perspectivas. In Ecologia de peixes de riachos (E.P. Caramaschi, R. Mazzoni \& P.R. Peres-Neto, eds.). PPGE-UFRJ, Série Oecologia Brasiliensis, Rio de Janeiro, vol. 6, p. 91-138.

SCHMIDT-NIELSEN, K. 1999. Fisiologia Animal: adaptação e meio ambiente. 5. Ed. São Paulo, Santos.

SHIBATTA, O.A., ORSI, M.L., BENNEMANN, S.T. \& SILVA-SOUZA, A.T. 2002. Diversidade e distribuição de peixes na bacia do rio Tibagi. In A bacia do rio Tibagi (M. E. MEDRI, E. BIANCHINI, O. A. SHIBATTA \& J.A. PIMENTA, eds.). Londrina: p. 403-423.

SMITH, W.S., BARRELA, W. \& CETRA, M. 1997. Comunidade de peixes como indicadora de poluição ambiental. Rev. Bras. Ecol. 1(1):67-71.

WOOTON, R.J. 1990. Fish and fisheries series 1: ecology of teleost fishes. Chapman and Hall, Nova Iorque.

Título: Peixes como indicadores da qualidade ambiental do ribeirão Esperança, município de Londrina, Paraná, Brasil.

Autores: Vieira, DB e Shibatta, OA

Biota Neotropica, Vol.7 (número 1): 2007

http://www.biotaneotropica.org.br/v7n1/pt/abstract?article+ bn01407012007

Recebido em 27/09/06 - Versão reformulada recebida em 20/12/06 - Publicado em 15/02/2007

ISSN 1676-0603 


\section{Anexo A}

Protocolo de avaliação rápida de diversidade de hábitats segundo Callisto et al. (2000).

\begin{tabular}{ccccc}
\hline Parâmetros de hábitat & $\begin{array}{c}\text { Ótimo } \\
(3 \text { pontos })\end{array}$ & $\begin{array}{c}\text { Sub-ótimo } \\
(2 \text { pontos })\end{array}$ & $\begin{array}{c}\text { Mediano } \\
(1 \text { ponto })\end{array}$ & $\begin{array}{c}\text { pobre } \\
(0 \text { pontos })\end{array}$ \\
\hline
\end{tabular}

1 - Tipos de fundos $\quad$ Mais de 50\% com há- 30 a 50\% de hábitats es- 10 a 30\% de hábitats Menos que $10 \%$ de hábitats bitats diversificados táveis, sem evidência de estáveis; substratos fre- estáveis; substrato instável ou (pedaços de tronco alteração por erosão ou qüentemente modifica- ausente. submersos, cascalho) assoreamento. dos. e estáveis.

2 - Largura dos remansos Rápidos e remansos Remansos com a largura Trechos rápidos podem Remansos rápidos ou inexisbem desenvolvidos; igual a do rio, mas com estar ausentes; remansos tentes. remansos tão largos comprimento menor que o não tão largos quanto o quanto o rio e com o dobro da largura do rio. rio e seu comprimento comprimento igual ao menor que o dobro da dobro da largura do largura do rio. rio.

3-Frequência de remansos Remansos relativamen- Remansos não freqüentes; Remansos ou curvas Geralmente com lâmina d'água (ou curvas) te freqüentes; distância distância entre remanes- ocasionais; hábitats for- "lisa" ou com remansos rasos; entre remansos dividida centes dividida pela largu- mados pelos contornos pobreza de hábitats; distância pela largura do rio entre ra do rio entre 7 e 15 . do fundo; distância entre entre remansos dividida pela 5 e 7. remansos dividida pela largura do rio $>25$ largura do rio entre 15 e 25 .

4-Tipo de substrato Seixos abundantes Seixos abundantes; casca- Fundo principalmente Fundo pedregoso; seixos au(principalmente em lho comum. formado por cascalho; sentes. nascentes de rios). alguns seixos presentes.

5 - Deposição de lama Entre 0 e $25 \%$ do fundo Entre 25 e $50 \%$ do fundo Entre 50 e $75 \%$ do fundo Mais de $75 \%$ do fundo coberto coberto por lama (silte coberto por lama. coberto por lama. por lama. e argila).

6 - Depósitos sedimentares Menos de 5\% do fundo Alguma evidência de mo- Deposição moderada de Grandes depósitos de lama, marcom deposição de lama; dificação no fundo, prin- cascalho novo, areia ou gens assoreadas; mais de 50\% ausência de deposição cipalmente aumento de lama nas margens, entre do fundo modificado; remansos nos remansos. Provável cascalho, areia ou lama; 30 e 50\% do fundo afeta- ausentes.

que a correnteza arraste 5 a $30 \%$ do fundo afeta- do; deposição moderada todo o material fino. do, suave deposição nos nos remansos.

remansos.

7 - Alteração do canal do Canalização (retifica- Alguma canalização Alguma modificação Margens cimentadas; acima de rio ção) ou dragagem au- presente, normalmente presente nas duas mar- $80 \%$ do rio modificado. sente ou mínima; rio próximo à construção gens; 40 a $80 \%$ do rio com padrão normal. de pontes; evidência de modificado. modificações há mais de 20 anos.

8 - Características do fluxo Fluxo relativamente Lâmina d'água acima de Lâmina d'água entre Lâmina d'água escassae presendas águas igual em toda a lar- $75 \%$ do canal do rio; ou 25 e $75 \%$ do canal do te apenas nos remansos. gura do rio; mínima menos de $25 \%$ do subs- rio, e/ou maior parte do quantidade de substrato trato exposto. exposta. substrato nos "rápidos" expostos.

\begin{tabular}{ll}
\hline $\begin{array}{l}\text { 9 - Presença de vegetação } \\
\text { ripária (cada margem) }\end{array}$ & Acima de $90 \%$ com Entre 70 e $90 \%$ com ve- Entre 50 e $70 \%$ com Menos de $50 \%$ da vegetação \\
& vegetaço ripária nati- getação ripária nativa; vegetação ripária nativa; ripária nativa; deflorestamento \\
& arbustos ou macrófitas; mas não afetando o desen- trechos com solo exposto \\
& mínima evidência de volvimento da vegetação; ou vegetação eliminada; \\
& desmatamento; todas maioria das plantas atin- menos da metade das \\
& as plantas atingindo a gindo a altura "normal". plantas atingindo a altura \\
& altura "normal".
\end{tabular}




\section{Anexo A}

Continuação...

\begin{tabular}{|c|c|c|c|c|}
\hline Parâmetros de hábitat & $\begin{array}{c}\text { Ótimo } \\
\text { (3 pontos) }\end{array}$ & $\begin{array}{l}\text { Sub-ótimo } \\
(2 \text { pontos })\end{array}$ & $\begin{array}{l}\text { Mediano } \\
\text { (1 ponto) }\end{array}$ & $\begin{array}{c}\text { pobre } \\
(0 \text { pontos })\end{array}$ \\
\hline $\begin{array}{l}10 \text { - Estabilidade das mar- } \\
\text { gens (cada margem) }\end{array}$ & $\begin{array}{l}\text { Margens estáveis; } \\
\text { evidência de erosão } \\
\text { mínima ou ausente; } \\
\text { pequeno potencial para } \\
\text { problemas futuros. Me- } \\
\text { nos de } 5 \% \text { da margem } \\
\text { afetada. }\end{array}$ & $\begin{array}{l}\text { Moderadamente estáveis; } \\
\text { pequenas áreas de erosão } \\
\text { freqüentes. Entre } 5 \text { e } 30 \% \\
\text { da margem com erosão. }\end{array}$ & $\begin{array}{l}\text { Moderadamente instá- } \\
\text { vel; entre } 30 \text { e } 60 \% \text { da } \\
\text { margem com erosão. } \\
\text { Risco elevado de erosão } \\
\text { durante enchentes. }\end{array}$ & $\begin{array}{l}\text { Instável; muitas áreas com ero- } \\
\text { são; freqüentes áreas descobertas } \\
\text { nas curvas do rio; erosão óbvia } \\
\text { entre } 60 \text { e } 100 \% \text { da margem. }\end{array}$ \\
\hline $\begin{array}{l}11 \text { - Extensão da vegetação } \\
\text { ripária (cada margem) }\end{array}$ & $\begin{array}{l}\text { Largura da vegetação } \\
\text { ripária > } 18 \mathrm{~m} \text {; sem } \\
\text { influência de ativida- } \\
\text { des antrópicas (pastos, } \\
\text { estradas, etc). }\end{array}$ & $\begin{array}{l}\text { Largura da vegetação ri- } \\
\text { pária entre } 12 \text { e } 18 \mathrm{~m} \text {; } \\
\text { mínima influência an- } \\
\text { trópica. }\end{array}$ & $\begin{array}{l}\text { Largura da vegetação } \\
\text { ripária entre } 6 \text { e } 12 \mathrm{~m} \text {; } \\
\text { influência antrópica in- } \\
\text { tensa. }\end{array}$ & $\begin{array}{l}\text { Largura da vegetação ripária me- } \\
\text { nor que } 6 \mathrm{~m} \text {; vegetação restrita } \\
\text { ou ausente devido à atividade } \\
\text { antrópica. }\end{array}$ \\
\hline
\end{tabular}

